\title{
PET: A Proton/Electron Telescope for Studies of Magnetospheric, Solar, and Galactic Particles
}

\author{
W. R. Cook, A. C. Cummings, J. R. Cummings, T. L. Garrard, B. Kecman, R. A. Mewaldt, \\ R. S. Selesnick, E. C. Stone, D. N. Baker, T. T. von Rosenvinge, J. B. Blake, and L. B. Callis
}

\begin{abstract}
The Proton/Electron Telescope (PET) on SAMPEX is designed to provide measurements of energetic electrons and light nuclei from solar, galactic, and magnetospheric sources. PET is an all solid-state system that will measure the differential energy spectra of electrons from $\sim 1$ to $\sim 30 \mathrm{MeV}$ and $\mathrm{H}$ and He nucle from $\sim 20$ to $\sim 300 \mathrm{MeV} /$ nuc, with isotope resolution of $\mathrm{H}$ and He extending from $\sim 20$ to $\sim 80 \mathrm{MeV} /$ nuc. As SAMPEX scans all local times and geomagnetic cutoffs over the course of its near-polar orbit, PET will characterize precipitating relativistic electron events during periods of declining solar activity, and it will examine whether the production rate of odd nitrogen and hydrogen molecules in the middle atmosphere by precipitating electrons is sufficient to affect $O_{3}$ depletion. In addition, PET will complement studies of the elemental and isotopic composition of energetic heavy $(Z>2)$ nuclei on SAMPEX by providing measurements of $\mathrm{H}, \mathrm{He}$, and electrons. Finally, PET has limited capability to identify energetic positrons from potential natural and man-made sources.
\end{abstract}

\section{INTRODUCTION}

B OTH the MAST and PET sensors on the polar-orbiting Solar, Anomalous, and Magnetospheric Particle Explorer (SAMPEX) were originally part of the Comprehensive Particle Analysis System (COMPAS) selected for flight on the U.S. spacecraft of the International Solar Polar Mission (ISPM), and MAST and PET are housed within a common box. As part of ISPM PET was designed to provide exploratory studies of energetic $\mathrm{H}, \mathrm{He}$, and electrons from solar and Galactic sources on ISPM's flight out of the ecliptic plane and over the solar poles. Although that spacecraft was canceled in 1981, midway through the construction of the MAST/PET instruments, MAST and PET were later proposed, and approved, for inclusion on SAMPEX, NASA's first Small Explorer (SMEX) mission. The response of both instruments is wellsuited for studying the diverse particle populations that will be encountered over the SAMPEX orbit.

PET is composed of an array of silicon solid state detectors that identify and measure the kinetic energy of electrons from $\sim 1$ to $\sim 30 \mathrm{MeV}$ and of $\mathrm{H}$ and $\mathrm{He}$ isotopes from $\sim 20$ to $\sim 80 \mathrm{MeV} /$ nuc. In addition PET includes a counting

Manuscript received August 3, 1992; revised January 21, 1993. This work was supported by NASA under Contract NAS5-30704 and Grant NAGW1919.

W. R. Cook, A. C. Cummings, J. R. Cummings, T. L. Garrard, B. Kecman, R. A. Mewaldt, R. S. Selesnick, and E. C. Stone are with the California Institute of Technology, Pasadena, CA 91125.

D. N. Baker and T. T. von Rosenvinge are with the Goddard Space Flight Center, Greenbelt, MD 20771.

L. B. Callis is with the Langley Research Center, Hampton, VA 23681

IEEE Log Number 9208073. rate for electrons $>0.4 \mathrm{MeV}$ and protons $>4 \mathrm{MeV}$ that has 0.1 second time resolution for studies of magnetospheric particles, and it has limited capability for identifying energetic positrons. In this paper we describe the operation of PET and summarize the scientific objectives that it will address. The Mass Spectrometer Telescope (MAST) is described in a companion paper in this volume by Cook et al. [1]. Also included in the SAMPEX payload are a Low Energy Ion Composition Analyzer (LEICA; see reference [2]) and a Heavy Ion Large Telescope (HILT; see [3]). For an overview of the SAMPEX mission, see Baker et al. [4].

\section{SCIENTIFIC OBJECTIVES}

\section{A. High Energy Magnetospheric Electron Precipitation}

Long-term observations in the outer magnetosphere demonstrate that energetic particle fluxes are strongly modulated by solar wind streams. Lower energy $(\leq 300 \mathrm{keV})$ particle fluxes track the solar wind variations quite closely and appear to be the direct product of magnetospheric substorm activity that is controlled by the solar wind. Higher energy $(\geq 300 \mathrm{keV})$ particle fluxes are also modulated by the solar wind streams, but are not directly related to substorm acceleration mechanisms. Since very energetic electrons may play a key role in linking together the magnetospheric-ionospheric-atmospheric system [5]-[9], it is an important element of applied magnetospheric science to understand solar wind influence on energetic electron acceleration and transport.

New results for relativistic magnetospheric electrons suggest interesting coupling possibilities that extend the traditional relativistic electron precipitation (REP) picture [7] in several ways. First, the energies of electrons that have been measured are far greater than those in REP events and thus the energy deposition, ionization, and chemistry modification will extend much deeper into the atmosphere than previously suspected [7], as illustrated in Fig. 1. Secondly, there is strong solar cycle variability in the multi-MeV electron component (see Fig. 2) which will, in turn, impose a strong variability on ionization and chemistry effects upon the middle atmosphere, possibly extending deep into the stratosphere. Thirdly, relatively broad midlatitudinal bands of the Earth's surface are involved, implying a truly global effect.

The PET sensor in the low, polar orbit of SAMPEX is well suited to monitor the precipitation of relativistic electrons into the upper atmosphere. It will make direct observations of electron precipitation over the energy range $0.4-30 \mathrm{MeV}$, 

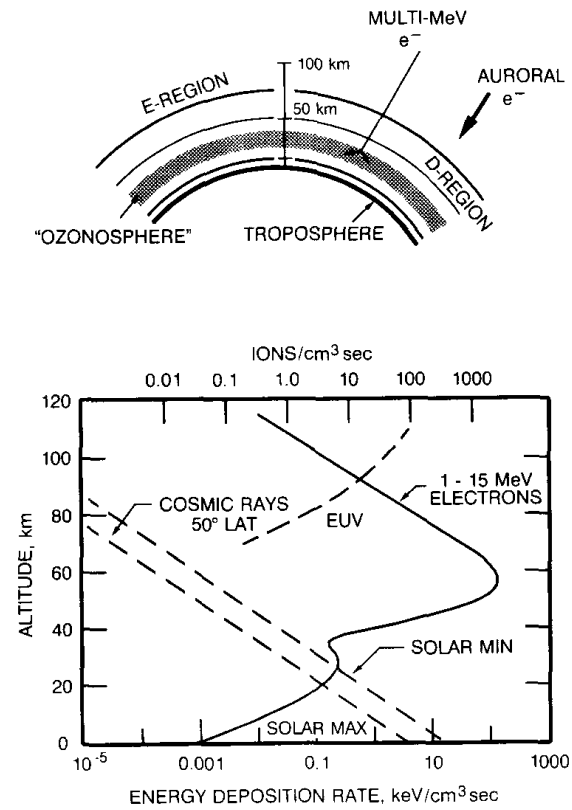

Fig. 1. (Top) A diagram illustrating the much greater depth to which precipitating relativistic electrons can penetrate into the Earth's atmosphere as compared to characteristically lower-energy auroral electrons. (Bottom) Multi-MeV electrons, when present, represent the dominant ionization source in the middle atmosphere $(40-80 \mathrm{~km}$ altitude). The figure shows the expected energy deposition versus altitude if an energetic (1-15 MeV) electron even observed at geostationary orbit were to precipitate into the atmosphere. This is contrasted with solar extreme ultraviolet (EUV) ionization at high altitude and the effect of galactic cosmic rays at low altitude.

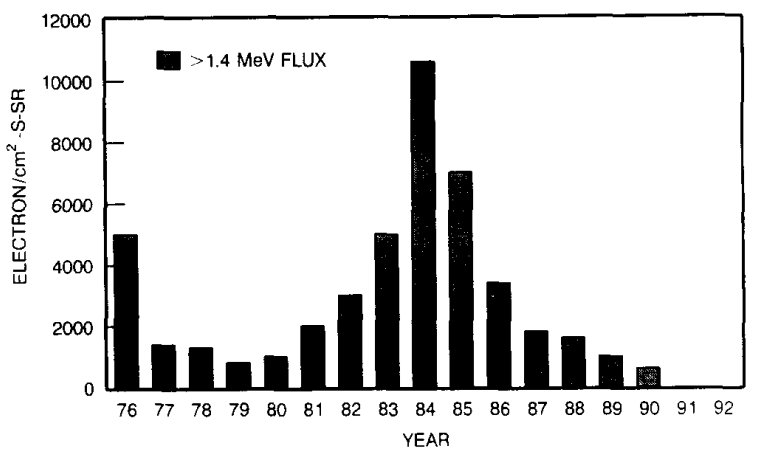

Fig. 2. Annual flux averages of the directional intensity of electrons with energies greater than $1.4 \mathrm{MeV}$ as measured by sensor systems at geostationary orbit alt. $=35,700 \mathrm{~km}(6.6 \mathrm{Re})$. A large flux maximum occurred in 1984 with minima in 1979 and 1990. This strong temporal variation is consistent with a significant solar cycle (11-year) dependence of relativistic outer-zone magnetospheric electrons.

measurements that are effectively impossible from a highaltitude spacecraft. The polar orbit will allow coverage at all latitudes, and, over the course of a day, rotation of the Earth under the SAMPEX orbit will allow coverge at all longitudes. Over the course of the mission coverage at all local times will be achieved. As Fig. 3 indicates, the SAMPEX mission should sample the time periods when both major solar flares and intense relativistic electron events reach their maximum frequency.

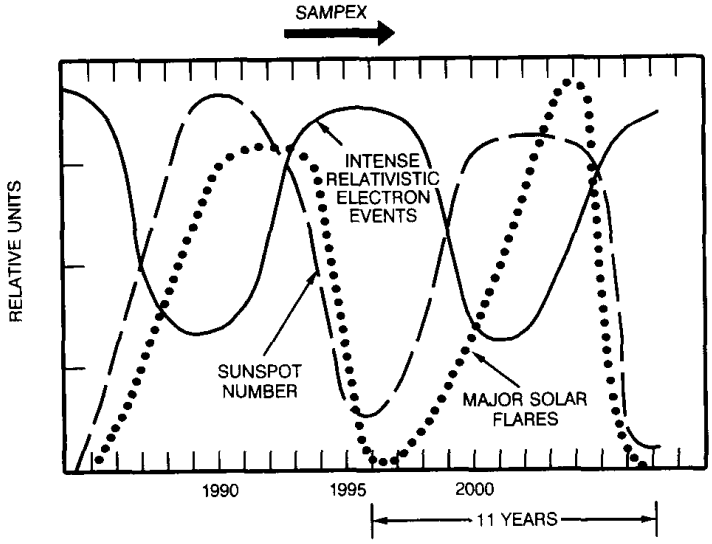

Fig. 3. A schematic illustration of the 11-year solar-cycle effects thought to occur in the solar terrestrial system. The long dash curve shows the relative sunspot number, or solar activity cycle. Major solar flares tend to track the sunspot number, often showing more events slightly after sunspot maximum. Intense relativistic electron events are in antiphase with sunspot number.

\section{B. Effects of Precipitating Electrons on the Middle Atmosphere}

Multi-MeV electrons can penetrate deeply into the atmosphere and model calculations show that they can dominate other sources of ionization in the middle altitude regions [7], as shown in Fig. 1. Solar energetic particle events and relativistic electron precipitation events can lead to significant atmospheric production of odd nitrogen $\left(\mathrm{NO}, \mathrm{NO}_{2}, \mathrm{NO}_{3}\right.$, $\mathrm{HNO}_{4}, \mathrm{~N}_{2} \mathrm{O}_{5}$, and $\left.\mathrm{ClONO}_{2}\right)$ and odd hydrogen $\left(\mathrm{H}, \mathrm{OH}, \mathrm{HO}_{2}\right.$, $\mathrm{H}_{2} \mathrm{O}_{2}$ ). This occurs through ion chemistry initiated by the atmospheric ion pair production associated with these events. Both of these chemical families are important to the global $\mathrm{O}_{3}$ balance [10], and hence to the thermal structure of the middle atmosphere. Thorne [5], [6] suggested that precipitating relativistic electrons, through the production of odd hydrogen and odd nitrogen, could lead to local $\mathrm{O}_{3}$ depletions in the $40-80 \mathrm{~km}$ region of the middle atmosphere. Callis et al. [8], [9] have carried out simulations which suggest that the production of odd nitrogen species in this altitude region and in the fall, winter and early spring, may be carried by the normally descending advective motions to the lower stratosphere. During these seasons, the photodissociation rates of $\mathrm{NO}$ are small, and due to the long lifetime of $\mathrm{NO}_{\mathrm{y}}$ in the mid-to-lower stratosphere, accumulation may occur with attendant $\mathrm{O}_{3}$ destruction. Events occurring in these seasons and in the polar night would certainly lead to accumulations of $\mathrm{NO}_{\mathrm{y}}$ and $\mathrm{HO}_{\mathrm{x}}$.

Large, recurrent solar wind streams emanating from persistent coronal holes are a prominent aspect of the Sun's 11-year and 22-year activity cycle. These coronal holes extend down to the solar equator and give rise to high speed solar wind streams at $\geq 1 \mathrm{AU}$ only during the approach to solar (sunspot) minimum. The high speed streams, in turn, strongly control the presence or absence of multi-MeV electrons in the Earth's outer magnetosphere. If relativistic electrons, when precipitated into the middle atmosphere, significantly modify $\mathrm{O}_{3}$ and $\mathrm{NO}_{\mathrm{y}}$ concentrations [6], [7], they could leverage and modify a much larger energy supply, viz., solar UV radiation. 
Thorne [5] suggested that modulation of stratospheric $\mathrm{O}_{3}$ might affect the thermal structure and radiative processes of the atmosphere. If such changes ocur in the $22-35 \mathrm{~km}$ region, zonal winds and planetary wave structure could be altered which may then affect tropospheric patterns. This could be a mechanism for producing an 11-year cycle in the Earth's middle and lower atmosphere. The radiative budget of the troposphere could also be affected.

It is conceivable that these chemical perturbations could also lead to substantial temperature changes in the mesosphere, with consequent changes in the phase and amplitude of the upwardly propagating long planetary waves, and changes in the energy deposition by these waves and by the breaking gravity waves. The $\mathrm{NO}_{\mathrm{x}}$ increases may also lead to changes in the D-region electron density.

\section{Man-Made Sources of Magnetospheric Particles}

The former Soviet Union has flown low-altitude, nearpolar satellites powered by nuclear reactors, the so-called RORSATS. When in operation the reactors emit intense fluxes of both neutrons and gamma rays. Pair production by the gamma flux in the skin of the vehicle creates electrons and positrons which are injected into the magnetosphere [11]. The energies of these particles range up to several $\mathrm{MeV}$ and are determined by the gamma-ray leakage spectrum. Although never reported, protons from the decay of reactor leakage neutrons must be injected as well, and might be detectable by the HILT sensor. The reactor serves as a point source for the pair-produced particles, whereas the neutron decay particles are not localized at the spacecraft. The neutrons decay in flight as they move away from the reactor, and thus the injection site will be the point of the decay, not the location of the reactor. The energy spectrum of the protons reflects the energy spectrum of the leakage neutrons.

If a satellite powered by a nuclear reactor is in operation in low Earth orbit during the SAMPEX mission, the pairproduced electrons and positrons will be readily detectable by the PET sensor. These particles are unlike particles injected by natural processes in that their origin is a true point source, albeit a moving one. In addition, positrons are well suited to serve as field-line tracers, providing the opportunity for detailed studies of the type pioneered by Hones et al. [11] of the near-Earth magnetic field-line geometry and atmospheric loss processes.

\section{Secondary Magnetospheric Particles}

Eastern European space scientists have repeatedly reported on observations of very energetic electrons and positrons ( $E \geq$ tens of $\mathrm{MeV}$ ) at SAMPEX altitudes (cf, [12], [13] and references therein). It has been suggested that these electrons are, at least in part, secondary particles from the interactions of inner-zone protons and galactic cosmic rays with the residual atmosphere. These interactions can lead to the creation of pions with the residual $\pi$ - $\mu$-e decays yielding highly relativistic electrons. If these electrons are injected into the magnetosphere at near $90^{\circ}$ pitch angle in the region of the South Atlantic Anomaly, the drift averaged atmospheric density can be sufficiently low to permit a relatively long particle lifetime. Thus they will be able to drift around the Earth many times before being removed by energy loss in the residual atmosphere due to ionization and bremstrahlung

The PET sensor, with its large geometry factor, and high time resolution, will permit a detailed study of this secondary magnetospheric particle population. These particles, which are able to penetrate deeply into the space vehicle because of their very high energy, are also of interest in completely defining the space station radiation environment.

\section{E. Solar Energetic Particles}

Recent comprehensive surveys of energetic particles accelerated in solar flares have shown that there are two general classes of such particle events: large events that are characterized by extended risetimes and relatively long durations, and somewhat smaller "impulsive" events that are typically marked by enhanced fluxes of heavy nuclei, the rare isotope ${ }^{3} \mathrm{He}$, and energetic electrons (see, e.g., [14]). Indeed, energetic electron fluxes are one of the most useful means of identifying impulsive solar flare events (e.g., [15]). PET will complement the composition studies of solar events to be carried out on SAMPEX by LEICA, HILT, and MAST [2], [3], [1] with measurements of 1 to $30 \mathrm{MeV}$ electrons, and by extending spectral studies of ${ }^{1} \mathrm{H},{ }^{3} \mathrm{He}$, and ${ }^{4} \mathrm{He}$ nuclei to the energy range from $\sim 20$ to $\sim 100 \mathrm{MeV} /$ nuc.

\section{F. Anomalous and Galactic Cosmic Ray Studies}

Among the primary objectives of SAMPEX are studies of the charge states and isotopic composition of the so-called "anomalous cosmic ray component." These low energy nuclei apparently originate from neutral interstellar atoms (including $\mathrm{H}, \mathrm{He}, \mathrm{C}, \mathrm{N}, \mathrm{O}, \mathrm{Ne}$, and $\mathrm{Ar}$ ) that have been swept into the heliosphere, singly ionized, and then accelerated at the solar wind termination shock to energies of $\sim 10$ to $10^{2} \mathrm{MeV} /$ nuc.

On SAMPEX the HILT and MAST instruments will use the geomagnetic field as a rigidity filter to measure the charge states of anomalous $\mathrm{He}, \mathrm{N}$, and $\mathrm{O}$, while MAST will measure the isotopic composition of $\mathrm{He}, \mathrm{N}, \mathrm{O}, \mathrm{Ne}$, and Ar. PET will complement these instruments by extending studies of anomalous He to higher energies( $100 \mathrm{MeV} /$ nuc) than before using the Earth's magnetic field to separate for the first time the relative contribution of $\mathrm{ACR}$ and galactic cosmic ray (GCR) He beyond $50 \mathrm{MeV} /$ nuc. PET measurements of the ${ }^{3} \mathrm{He} /{ }^{4} \mathrm{He}$ ratio will aid in this effort by using ${ }^{3} \mathrm{He}$ as a tracer of the GCR component, since there is negligible anomalous ${ }^{3} \mathrm{He}$. PET will also search for evidence of predicted fluxes of anomalous $\mathrm{H}$ at $\sim 100 \mathrm{MeV} /$ nuc that may penetrate into the inner solar system at times of minimum solar modulation [16], [17].

\section{INSTRUMENT DESCRIPTION}

\section{A. The Telescope}

The PET telescope, shown schematically in Fig. 4, consists of a series of eight Li-drifted silicon detectors (P1 to P8) with thicknesses ranging from 2 to $15 \mathrm{~m}$. The telescope opening aperture is defined by a passive collimator, followed by two 
TABLE I

PET Detector, ADC, AND Discriminator Characteristics

\begin{tabular}{llllllll}
\hline $\begin{array}{l}\text { Detector } \\
\text { Name }\end{array}$ & $\begin{array}{l}\text { Nominal } \\
\text { Thickness } \\
(\mathrm{mm})\end{array}$ & $\begin{array}{l}\text { Central } \\
\text { Active } \\
\text { Area } \\
\left(\mathrm{cm}^{2}\right)\end{array}$ & $\begin{array}{l}\text { Guard } \\
\text { Active } \\
\text { Area } \\
\left(\mathrm{cm}^{2}\right)\end{array}$ & $\begin{array}{l}\text { Nominal } \\
\text { ADC } \\
\text { Threshold } \\
(\mathrm{MeV})\end{array}$ & $\begin{array}{l}\text { Nominal } \\
\text { ADC Full } \\
\text { Scale } \\
(\mathrm{MeV})\end{array}$ & $\begin{array}{l}\text { Nominal } \\
\text { Discriminator } \\
\text { Thresholds } \\
(\mathrm{MeV})\end{array}$ & $\begin{array}{l}\text { Guard } \\
\text { Discriminator } \\
\text { Thresholds } \\
(\mathrm{MeV})\end{array}$ \\
\hline P1 & 2 & 8.0 & - & 0.35 & 157 & P1A = 3.1 & - \\
P2 & 2 & 8.0 & - & 0.35 & 157 & - & - \\
P3 & 15 & 9.2 & 4.5 & 0.7 & 317 & P3A = 2.8 & $0.3,5$ \\
P4-P7 & 3 & & & & & P3B=12 & 0.23 \\
P8 & 3 & 4.5 & 8.0 & 0.36 & 337 & 0.23 & $0.3,1.2$ \\
\hline
\end{tabular}

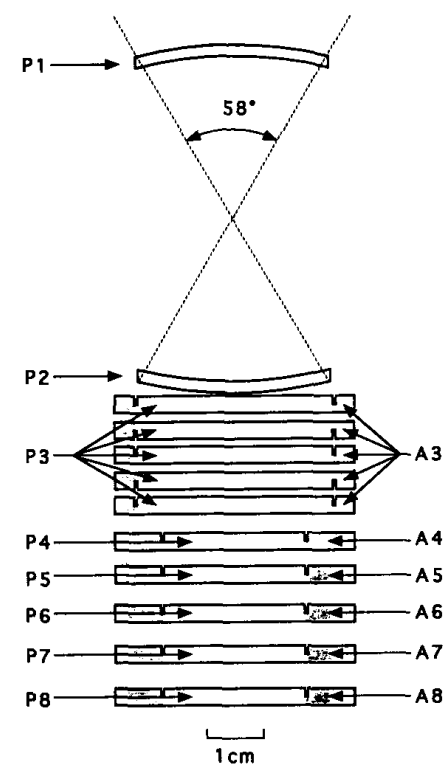

Fig. 4. Schematic of the PET Telescope. The primary analysis mode requires $\mathrm{P} 1$ and $\mathrm{P} 2\left(58^{\circ}\right.$ field of view); a "wide-angle" $90^{\circ}$ FOV that requires $\mathrm{P} 2$ and $\mathrm{P} 4$ but not $\mathrm{P} 1$ is also available for electrons. Detector parameters are summarized in Table I. The regions labeled A4 through A8 are annular "guard" regions used to detect particles that enter or leave through the side of the stack.

curved (spherical) aperture detectors (P1 and $\mathrm{P} 2$ ) designed to minimize pathlength variations over the telescope's $58^{\circ}$ opening angle. They are followed by eight flat detectors (P3 through $\mathrm{P} 8$ ), where the $\mathrm{P} 3$ detector is comprised of five identical devices with a combined thickness of $15 \mathrm{~mm}$. Detectors P3 through P8 are double-grooved devices with a central area for measuring energy loss and an annular guard region (labeled $\mathrm{A}$ ) used to detect particles that enter or leave through the side of the telescope, a design used previously on Voyager 1\&2 [18] and ISEE-3 [19].

Particles satisfying the P1.P2 coincidence enter through a $1.5 \mathrm{~cm}$ long collimator (not shown in Fig. 4) that is nominally $0.75 \mathrm{~mm}$ thick at its thinnest point, and that preserves the $58^{\circ}$ opening angle. The collimator also supports two windows (each $12.5 \mu \mathrm{m}$ thick aluminized Kapton) that provide electrical shielding and protection from sunlight.

Detectors P1, P2, and the center of P3 are each direct coupled to separate charge-sensitive preamplifiers, shaping amplifiers, and 10-bit ADC's. The summed output of the centers of P4 through P7 is fed into a fourth 10-bit ADC. The center of D8, and the guard regions of D3 to D8 are each connected to preamplifiers, shaping amplifiers and discriminators. Each guard signal channel has two discriminators: A1 is sensitive to minimum ionizing particles while the A2 levels are $\sim 1.2 \mathrm{MeV}$ for A4-A8 and $\sim 5 \mathrm{MeV}$ for A3. Table I summarizes the characteristics of the PET detectors and their analysis chains.

Packaging PET within the available size and mass constraints was accomplished by using custom hybrid circuitry on planar multilayer printed circuit boards. PET includes a total of 79 hybrids, including 12 pre-post amplifiers, 15 test pulsers, 13 discriminators, and $4 \mathrm{ADCs}$ that are each comprised of two hybrid circuits.

\section{B. Analysis Modes}

PET uses the conventional $d E / d x$-total energy technique to identify electrons, protons, and heavier nuclei, an approach which is based on the range-energy relations of energetic particles. With this approach a comparison of the rate of energy loss of energetic particles with their total energy loss can be used to identify both the charge and mass of energetic nuclei, as well as measure their kinetic energy. In practice, the rate of energy loss is determined by measuring the energy loss $(\Delta E)$ in a detector of known thickness, such as $\mathrm{P} 1$ or $\mathrm{P} 2$ on PET. In order to minimize the variations in the pathlength over the telescope's $58^{\circ}$ opening angle, $\mathrm{P} 1$ and $\mathrm{P} 2$ have been constructed from spherical segments of silicon. As a result PET should be capable of identifying elements from $\mathrm{H}$ to $\mathrm{Ni}$ ( $Z=1$ to 28 ), with isotope identification extending through $\mathrm{Ne}(Z=10)$. Although the range-energy characteristics of electrons are not nearly so precise as those of nuclei, electrons are easily separable from protons because of their much lower rate of energy loss.

PET includes a number of separate analysis modes that are designed to identify electrons and nuclei over selected energy intervals. We describe here the primary "Lo-Z" mode planned for nominal operations, in which PET provides the differential energy spectra of electrons and of $\mathrm{H}$ and $\mathrm{He}$ nuclei. A commandable "Hi- $\mathrm{Z}$ " mode, in which the gain of $\mathrm{P} 1, \mathrm{P} 2$, and $\mathrm{P} 3$ is reduced by a factor of ten, also allows PET to measure the energy spectra of the elements from $\mathrm{Li}$ to $\mathrm{Ni}(Z=3$ to 28). Although it is not presently planned to use this mode during normal operations, it provides a possible backup for the MAST and HILT sensors on SAMPEX. 
TABLE II

PET RESPONSE

\begin{tabular}{|c|c|c|c|c|c|c|}
\hline \multirow[b]{2}{*}{ Particle } & \multirow[b]{2}{*}{$\begin{array}{l}\text { Nominal } \\
\text { Energy Interal } \\
\text { (MeV or } \\
\mathrm{MeV} / \mathrm{nuc} \text { ) }\end{array}$} & \multirow[b]{2}{*}{$\begin{array}{l}\text { Typical } \\
\text { Geometry } \\
\text { Factor (1) } \\
\left(\mathrm{cm}^{2} \mathrm{sr}\right)\end{array}$} & \multirow[b]{2}{*}{$\begin{array}{l}\text { Detector }(2,3) \\
\text { Combination }\end{array}$} & \multicolumn{3}{|c|}{ Associated Counting Rates } \\
\hline & & & & Name & $\begin{array}{l}\text { Resolution } \\
(\mathrm{sec})\end{array}$ & $\begin{array}{l}\text { Duty } \\
\text { Cycle }\end{array}$ \\
\hline \multirow[t]{5}{*}{ Electrons } & $>0.4$ & 10 & P1 & P1 & 0.1 & 0.5 \\
\hline & $\sim 1-4$ & 1.8 & $\mathrm{P} 1 \cdot \overline{\mathrm{P} 1 \mathrm{~A}} \cdot \mathrm{P} 2 \cdot \overline{\mathrm{P} 3} \cdot \overline{\mathrm{A}}$ & ELO & 6 & 1 \\
\hline & $\sim 4-20$ & $1.7-1.1$ & $\frac{\mathrm{P} 1}{\mathrm{P} 4} \cdot \overline{\mathrm{P} 1 \mathrm{~A}} \cdot \mathrm{P} 2 \cdot \mathrm{P} 3$. & EHI & 6 & 1 \\
\hline & $\sim 12-30$ & $0.5-0.3$ & $\mathrm{P} 1 \cdot \mathrm{P} 2 \cdot \mathrm{P} 4 \cdot \overline{\mathrm{P} 8} \cdot \overline{\mathrm{A}}$ & RNG & 6 & 1 \\
\hline & $\sim 12-30$ & $2.8-0.9$ & $\overline{\overline{\mathrm{P} 1}} \cdot \frac{\mathrm{P} 2}{\overline{\mathrm{P} 8}} \cdot \overline{\mathrm{A}} \cdot \overline{\mathrm{P}} \overline{\mathrm{B}} \cdot \mathrm{P} 4$ & EWG & 6 & 1 \\
\hline \multirow[t]{5}{*}{$\mathrm{H}, \mathrm{He}$} & $>4$ & 10 & PI & P1 & 0.1 & 0.5 \\
\hline & $19-28$ & 1.8 & $\mathrm{P} 1 \mathrm{~A} \cdot \mathrm{P} 2 \cdot \overline{\mathrm{P}} 3 \cdot \overline{\mathrm{A}}$ & PLO & 6 & 1 \\
\hline & $28-64$ & $1.7-1.1$ & $\mathrm{P} 1 \mathrm{~A} \cdot \mathrm{P} 2 \cdot \mathrm{P} 3 \cdot \overline{\mathrm{P} 4} \cdot \overline{\mathrm{A}}$ & PHI & 6 & 1 \\
\hline & $64-85$ & $0.5-0.3$ & $\mathrm{P} 1 \cdot \mathrm{P} 2 \cdot \mathrm{P} 4 \cdot \overline{\mathrm{P}} 8 \cdot \overline{\mathrm{A}}$ & RNG & 6 & 1 \\
\hline & $>85$ & 0.3 & P1.P2.P8. $\bar{A}$ & PEN & 6 & 1 \\
\hline$Z \geq 3$ Nuclei (4) & $60-200$ & $1.7-1.1$ & $\mathrm{P} 1 \cdot \mathrm{P} 2 \cdot \overline{\mathrm{P}} 4 \cdot \overline{\mathrm{A}}$ & PLO, PHI & 6 & 1 \\
\hline
\end{tabular}

(1) Based on calculation with straight tracks; accelerator calibration data will modify values for electrons.

(2) "A" represents the logical "or" of the guard rings on P3 to P8.

(3) P1A, P3A, and P3B are digital discriminators on the P1 and P3 outputs set at 3.1, 2.8, and $12 \mathrm{MeV}$, resp.

(4) Commandable mode for $\mathrm{Z} \geq 3$ nuclei; energy range indicated is for Si-28.

The pulse height analysis of an "Event" is triggered whenever one of the coincidence equations in Table II is satisfied. The results, along with other information such as the state of various discriminators, are stored in one of five separate event buffers. These event buffers are read out into the telemetry stream by a rotating priority system that ensures that all event types are represented under conditions that range from periods dominated by intense fluxes of solar flare nuclei to periods domniated by trapped protons and electrons.

Because the telemetry rate is insufficient to transmit every event, rate accumulators are used to count events during 6-s intervals. A total of 32 such "counting rates" record instrument live time, the frequency of electrons and nuclei in several energy intervals defined by the coincidence logic, and the triggering frequency of a variety of discriminator levels. Table II summarizes some of the counting rates of physical interest. In addition, the "singles" counting rate of the front detector (P1) is sampled for $0.05 \mathrm{~s}$ out of every $0.10 \mathrm{~s}$ to measure the flux of magnetospheric electrons $>0.4 \mathrm{MeV}$ and protons $>4 \mathrm{MeV}$ on a fast time scale. This "high-resolution rate" is recorded whenever the count rate exceeds a (commandable) level of $\sim 50$ counts/s. All of the coincidence equations and some of the discriminator levels can be modified by command to allow for the possibility of noisy or failed detectors, and to optimize the instrument's response to the various particles of interest.

\section{Calibrations}

The response of PET to electrons has been calibrated over the energy range from $\sim 0.3$ to $\sim 27 \mathrm{MeV}$ with electron beams incident at a variety of energies and zenith angles. At higher energies the linear electron accelerator at the EG\&G Santa Barbara facility was operated in a low-intensity mode to provide monoenergetic beams at fourteen separate energies from 1.5 to $27 \mathrm{MeV}$. Calibrations at somewhat lower energies ( 0.3 to $3 \mathrm{MeV}$ ) were carried out with a beta spectrometer. PET was also calibrated with radioactive sources to determine its positron detection efficiency and its response to gamma rays that Compton scatter in the telescope producing a possible background for electron and positron measurements. For accelerator calibrations, where beam time is often limited and expensive, PET has a special port that allows events to be read out at rates of several thousand per second.

PET has a built-in internal calibrator that can be initiated either periodically (every 6.8 hours) or by command (see also [1]). The calibrator includes an 8-bit DAC that supplies reference voltages to the test-pulsers of each of the signal channels. The test pulsers can be stimulated either individually, or in groups, to perform limited tests of the coincidence logic, measure the thresholds of the various discriminators, and check the gain, linearity, and long-term stability of the ADCs. Calibration "events" are flagged and stored in a special buffer for read out and telemetry along with the regular data.

\section{Positron Detection with PET}

Although designed primarily for measurements of electrons, $\mathrm{H}$, and $\mathrm{He}$, PET also has limited efficiency for identifying $\sim 1$ to $\sim 20 \mathrm{MeV}$ positrons. When a low energy positron stops and annihilates in the telescope, one of the two 0.511 $\mathrm{MeV}$ annihilation gamma rays may Compton-scatter and be detected in a later detector, a technique used successfully in similar telescopes flown on IMP-7\&8 [20], [21]. An example of a positron-like event signature for positrons stopping in 


\begin{tabular}{ll} 
& \multicolumn{1}{c}{ TABLE III } \\
& PET RESOURCES \\
\hline Mass & $7.5 \mathrm{~kg}$ (including MAST) \\
Power & $1.2 \mathrm{~W}$ \\
Bit Rate & $500 \mathrm{bps}$ (orbit average) \\
\hline
\end{tabular}

$\mathrm{P} 2$ is $\mathrm{P} 1 \cdot \mathrm{P} 2 \cdot \overline{\mathrm{P}} 3 \cdot(\mathrm{P} 4+\mathrm{P} 5+\mathrm{P} 6+\mathrm{P} 7) \cdot \overline{\mathrm{P}} 8$, where the energy loss in the earlier detectors (P1 and $\mathrm{P} 2$ ) must be consistent with that of an electron, where P3 must not trigger, and where the pulse height in the later detector (P4, P5, P6, or P7) must be $\leq 0.34 \mathrm{MeV}$, the maximum-energy Compton-recoil from a $0.511 \mathrm{MeV}$ gamma ray. The estimated efficiency for identifying P1.P2 positrons with this signature is $\sim 0.003$. For somewhat higher energy positrons that stop in P3 the corresponding efficiency is estimated to be $\sim 0.005$.

The capability of PET to detect positrons was verified by calibrations with a Ge-68 $\beta^{+}$-decay source prior to launch. Further analysis of these data, combined with Monte Carlo simulations, will establish the positron detection efficiency. The principal source of background for positron measurements is expected to be gamma rays that Compton-scatter in two separate detectors (see [20] and [21]).

\section{E. Resources}

The MAST and PET instruments on SAMPEX are housed in a common box of dimensions $25 \mathrm{~cm} \times 36 \mathrm{~cm} \times 17 \mathrm{~cm}$, with the two cylindrical telescopes extending $\sim 6 \mathrm{~cm}$ above the box. Power is provided by a supply housed in a separate box of dimensions $13 \mathrm{~cm} \times 12 \mathrm{~cm} \times 6 \mathrm{~cm}$. Table III summarizes the spacecraft resources required by PET. Although they share a common power supply, MAST and PET are electrically isolated. The peak power drawn by the instruments during large flares may increase by $\sim 25 \%$. PET's average data rate of $0.5 \mathrm{kbps}$ corresponds to $\sim 9$ transmitted events per second. However, PET may achieve significantly higher data rates during limited periods of activity through the novel data management approach of the SAMPEX Data Processing Unit (see [22]). During launch operations both the MAST and PET telescopes were acoustically and thermally protected by a common $0.08 \mathrm{~cm}$-thick $\mathrm{Al}$ cover that pwas opened by command prior to instrument turn-on.

\section{ACKNOWLEDGMENT}

Essential contributions to the implementation of the PET experiment were made by J. H. Marshall and T. Harrington of MDH, Ind.; Ball Brothers Western Laboratories under the direction of D. Snyder and G. Takahashi; D. Aalami of Space Instruments, Inc.; the Applied Science Division of PerkinElmer, under the direction of N. Preketes; F. Shaffer of Goddard Space Flight Center; and W. Althouse, B. Gauld, K. Hargreaves, and R. Vogt of Caltech.

\section{REFERENCES}

[1] W. R. Cook, A. C. Cummings, J. R. Cummings, T. L Garrard, B Kecman, R. A. Mewaldt, R. S. Selesnick, E. C. Stone, and T. T. von Rosenvinge, "MAST: A Mass Spectrometer Telescope for isotope studies of solar, anomalous, and galactic cosmic rays," IEEE Trans. Geosci. Remote Sensing, vol. 31, pp. 557-564, May 1993.

[2] G. M. Mason, D. C. Hamilton, P. H. Walpole, K. F. Heuerman, T. L. James, M. H. Lennard, and J. E. Mazur, "LEICA: A Low Energy
Ion Composition Spectrometer for the study of solar and magnetospheric heavy ions," IEEE Trans. Geosci. Remote Sensing, vol. 31, pp. 549-556, May 1993.

[3] B. Klecker, D. Hovestadt, M. Sholer, H. Arbinger, M. Ertl, H. Kastle, E. Kunneth, P. Laeverenz, and E. Seidenschwang, "HILT: A Heavy Ion Large Proportional Counter Telescope for solar and anomalous cosmic rays," IEEE Trans. Geosci. Remote Sensing, vol. 31, pp. 542-548, May 1993.

[4] D. N. Baker, G. M. Mason, O. Figueroa, G. Colon, J. G. Watzin, and R. M. Aleman, "An overview of the Solar Anomalous and Magnetospheric Particle Explorer (SAMPEX) Mission,” IEEE Trans. Geosci. Remote Sensing, vol. 31, pp. 531-541, May 1993.

[5] R. M. Thorne, "Energetic radiation belt precipitation: A natural depletion mechanism for stratospheric ozone," Science, vol. 21, pp. 287-289, 1977.

[6] R. M. Thorne, "The importance of energetic particle precipitation on the chemical composition of the middle atmosphere," Pure Appl. Geophys., vol. 118 , p. 128,1980 .

[7] D. N. Baker, J. B. Blake, D. J. Gorney, P. R. Higbie, R. W. Klebesadel and J. H. King, "Highly relativistic electrons: A role in coupling to the middle atmosphere," Geophys. Res. Lett., vol. 14, pp. 1027-1030, 1987.

[8] L. B. Callis, D. N. Baker, J. B. Blake, J. D. Lambeth, R. E. Boughner, M. Natarajan, R. W. Klebesadel, and D. J. Gorney, "Precipitating relativistic electrons: Their long-term effect on stratospheric odd nitrogen levels," J. Geophys. Res., vol, 96, pp. 2939-2976, 1991.

[9] L. B. Callis, R. E. Boughner, M. Natarajan, J. D. Lambeth, D. N. Baker, and J. B. Blake, "Ozone depletion in the high latitude lower stratosphere: 1979-1990," J. Geophys. Res., vol. 96, pp. 2921-2937, 1991.

[10] G. Brasseur and S. Solomon, Aeronomy of the Middle Atmosphere. Dordrecht/Boston/Lancaster: D. Reidel Publishing Company, 1984

[11] E. W. Hones and P. R. Higbie, "Distribution and detection of positrons from an orbiting nuclear reactor," Science, 244, p. 448, 1989.

[12] S. A. Averin, A. M. Galper, V. M. Grachev, V. V. Dmitrenko, V. D Maslov, and S. E. Ulin, "High-energy electrons in the earth's external radiation belt," Cosmic Research, vol. 26, p. 274, 1988.

[13] L. V. Kurnosova, L. A. Razorenov, and M. I. Fradkin, "Flux of electrons with energies above $100 \mathrm{MeV}$ in the earth's inner radiation belts," Cosmic Research, vol. 29, p. 609, 1992.

[14] R. P. Lin, "Solar particle acceleration and propagation," Reviews of Geophysics, vol. 25, pp. 676-684, 1987.

[15] D. V. Reames, H. V. Cane, and T. T. von Rosenvinge, "Energeticparticle abundances in solar electron events," Ap. J., vol. 257, pp. 259-270, 1990.

[16] E. R. Christian, A. C. Cummings, and E. C. Stone, "Evidence for anomalous cosmic ray hydrogen," Ap. J. Letters, vol. 334, pp. L77-L80, 1989.

[17] R. A. Mewaldt, "Temporal variations of anomalous cosmic rays and further evidence for anomalous cosmic ray hydrogen," Proc. 21st International Cosmic Ray Conference (Adelaide), vol. 6, pp. 160-163, 1990.

[18] E. C. Stone, R. E. Vogt, F. B. McDonald, B. J. Teegarden, J. H. Trainor, J. R. Jokipii, and W. R. Webber, "Cosmic ray investigation for the Voyager missions; Energetic particle studies in the outer heliosphere-and beyond," Space Science Reviews, vol. 21, pp. 355-376, 1977.

[19] W. E. Althouse, A. C. Cummings, T. L. Garrard, R. A. Mewaldt, E. C. Stone, and R. E. Vogt, "A cosmic ray isotope spectrometer," Geoscience Electronics, vol. 16, pp. 204-207, 1978.

[20] G. J. Hurford, R. A. Mewaldt, E. C. Stone, and R. E. Vogt, "Observations of the ratio of low-energy cosmic-ray positrons and electrons during solar quiet times," Proceedings 13th International Cosmic Ray Conference (Denver), vol. 1, pp. 330-335, 1973.

[21] R. A. Mewaldt, E. C. Stone, and R. E. Vogt, "The quiet time flux of 0.16 to $1.6 \mathrm{MeV}$ positrons," Proceedings 14th International Cosmic Ray Conference (Munich), vol. 1, p. 401, 1975.

[22] D. J. Mabry, S. J. Hansel, and J. B. Blake, "The SAMPEX Data Processing Unit (DPU)," IEEE Trans. Geosci. Remote Sensing, vol. 31, pp. 572-574, May 1993.

Walter R. Cook, for a biography, please see page 563 of this issue.

Alan C. Cummings, for a photograph and biography, please see page 563 of this issue. 
Jay R. Cummings, for a photograph and biography, please see page 563 of this issue.

Thomas L. Garrard, for a photograph and biography, please see page 563 of this issue.

Branislav Kecman, for a photograph and biography, please see page 563 of this issue.

Richard A. Mewaldt, for a photograph and biography, please see page 563 of this issue.

Richard S. Selesnick, for a photograph and biography, please see page 564 of this issue.

Edward C. Stone, for a photograph and biography, please see page 564 of this issue.

Daniel N. Baker, for a photograph and biography, please see page 541 of this issue.
Tycho von Rosenvinge, for a biography, please see page 564 of this issue.

J. B. Blake received the B.S. degree in engineering physics and the M.S. and Ph.D. degrees in physics from the University of Illinois.

He joined the Aerospace Corporation in 1962, where he is presently Department Director of the Space Particles and Fields Department in the Space and Environment Technology Center. His recent work has concentrated on particles and fields in planetary magnetospheres, cosmic-ray physics, and nuclear astrophysics. He is Co-Investigator on the NASA Solar, Anomalous, and Magnetospheric Explorer (SAMPEX) mission, and Principal Investigator for the Comprehensive Energetic Particle Pitch Angle Distribution (CEPPAD) experiment on the NASA POLAR mission.

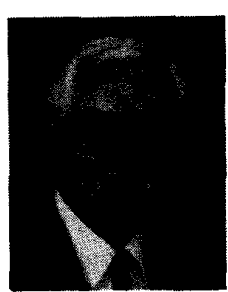

Len B. Callis received the B.S. degree in aerospace engineering from Virginia Polytechnic Institute and the M.S. degree in aerospace engineering from Cornell University.

$\mathrm{He}$ has been at the NASA Langley Research Center since 1962 and is currently a Senior Research Scientist in the Atmospheric Sciences Division. Recently, his research work has concentrated on magnetospheric-atmospheric coupling via precipitating relativistic electrons. He is currently a Co-investigator on the Solar, Anomalous, and Magnetospheric Particle Explorer (SAMPEX). 